\title{
CURRÍCULO E GESTÃO ESCOLAR COM PAULO FREIRE EM UM TERRENO PÓS-MODERNO CRÍTICO
}

\section{CURRICULUM AND SCHOOL MANAGEMENT WITH PAULO FREIRE FROM A CRITICAL POSTMODERN PERSPECTIVE}

\section{CURRÍCULO Y GESTIÓN ESCOLAR CON PAULO FREIRE EN UN TERRENO POST-MODERNO CRÍTICO}

\author{
Éderson Andrade \\ Doutor em Educação \\ Centro Universitário de Várzea Grande - UNIVAG \\ e-mail: ederson.andrade@univag.edu.br
}

\author{
Sávio Antunes dos Santos \\ Mestre em Educação \\ Centro de Formação dos Profissionais da Educação de Mato Grosso - CEFAPRO \\ e-mail: savioantunes1@hotmail.com
}

\section{RESUMO}

O objetivo deste artigo foi analisar concepções pedagógicas que contribuem para a abertura de questões curriculares e de gestão escolar na obra de Paulo Freire, bem como compreender como esses pensamentos podem se localizar em uma perspectiva pós-moderna crítica. $\mathrm{O}$ trabalho tem um corte qualitativo, descritivo e bibliográfico. Os dados foram organizados tomando por base três obras de Paulo Freire: A educação na cidade, Pedagogia do Oprimido e Pedagogia da Autonomia. A análise dos discursos que constituem as três obras selecionadas foi feita operando com alguns conceitos da Teoria do Discurso de Ernesto Laclau e Chantal Mouffe. Os resultados demonstram que o pensamento de Paulo Freire não se enquadra em uma perspectiva teórico-metodológica fixa, tendo a abertura e flexionamento como bases para as construções de suas propostas. Conclui-se que o pensamento freiriano é potente para a compreensão do currículo e da gestão escolar na contemporaneidade, uma vez que privilegia as relações dialógicas construídas das redes de sujeitos, num espaço tempo pós-moderno crítico.

Palavras-chave: Paulo Freire. Pós-Moderno Crítico. Currículo. Gestão Escolar.

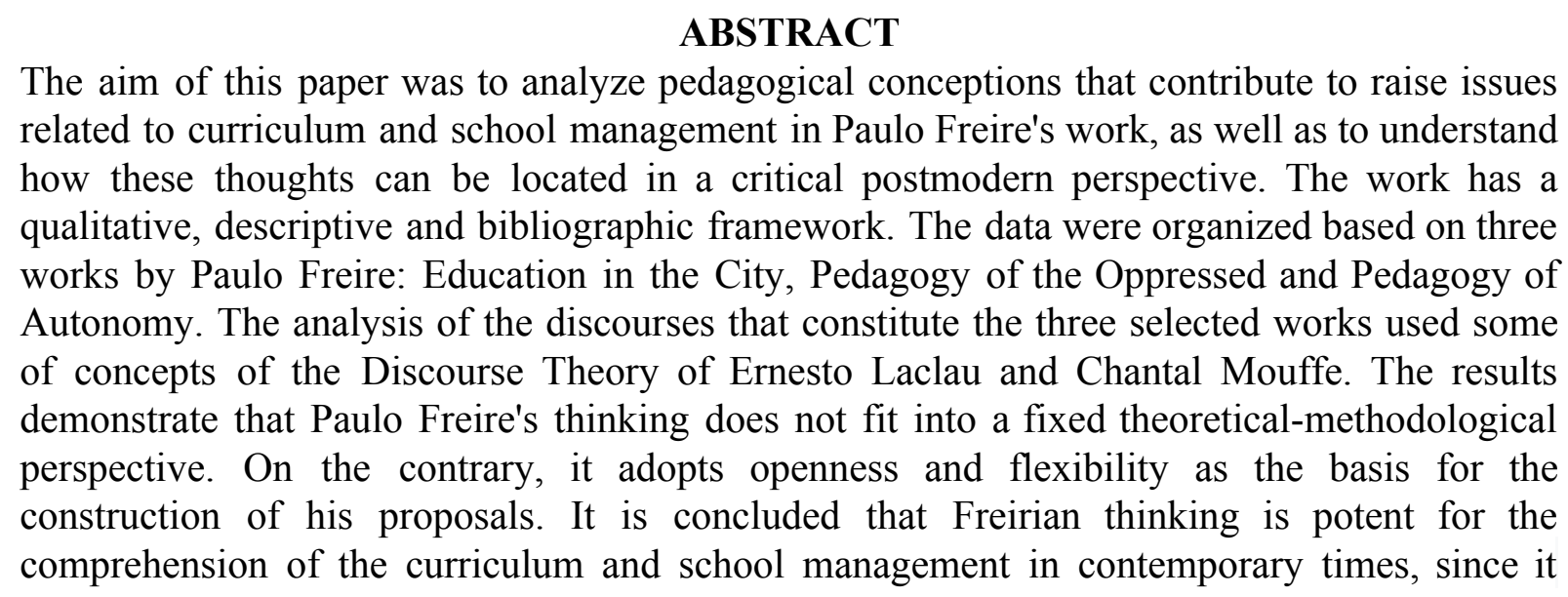


privileges the dialogic relations built from the networks of subjects, in a critical postmodern time and space.

Keywords: Paulo Freire. Critical Postmodern Perspective . Curriculum. School management.

\section{RESUMEN}

El objetivo de este trabajo fue analizar las concepciones pedagógicas que contribuyen a la apertura de los temas curriculares y de gestión escolar en el trabajo de Paulo Freire, así como comprender cómo estos pensamientos pueden ubicarse en una perspectiva posmoderna crítica. El trabajo tiene una sección cualitativa, descriptiva y bibliográfica. Los datos fueron organizados en base a tres obras de Paulo Freire: Educación en la ciudad, Pedagogía de los oprimidos y Pedagogía de la autonomía. El análisis de los discursos que constituyen las tres obras seleccionadas se realizó operando con algunos conceptos de la teoría del discurso de Ernesto Laclau y Chantal Mouffe. Los resultados demuestran que el pensamiento de Paulo Freire no encaja en una perspectiva teórico-metodológica fija, con la apertura y la flexión como base para la construcción de sus propuestas. Se concluye que el pensamiento freiriano es potente para la comprensión del currículo y la gestión escolar en los tiempos contemporáneos, ya que privilegia las relaciones dialógicas construidas a partir de las redes de asignaturas, en un espacio de tiempo crítico posmoderno.

Palabras-clave: Paulo Freire. Post-Moderno Crítico. Currículo. Gestión Escolar.

\section{INTRODUÇÃO}

Ao terem acesso ao título deste artigo, muitos leitores poderão se deparar com várias perguntas de imediato. Elencaremos duas possibilidades questionadoras: como podemos dizer que Paulo Freire (um pensador progressista/crítico) foi um "descabeçado" pós-moderno? Como podemos dizer que Paulo Freire (um pensador crítico) foi um crítico pós-moderno? Acrescentaríamos mais duas questões para o debate: por que enquadrar Paulo Freire em um espaço tempo fixo de pensamento? Por que não pensar as potencialidades críticas que Paulo Freire nos proporcionou em suas obras às análises sociais e educativas de nosso e de qualquer tempo? Para essa última pergunta, acreditamos que sim, podemos e devemos pensar com Freire, considerando que, pensar com Paulo Freire, um pensador progressista/crítico pós-moderno, pode nos ser potente para compreendermos questões do nosso tempo, um tempo pós-moderno marcado pelas incertezas, pela velocidade, pelas fissuras, pela indecidibilidade. Pretendemos, a partir da análise da obra de Paulo Freire, defender a posição que seus pensamentos são potentes para pensar o movimento que o nosso mundo possui, isso sem prender Paulo Freire na "corrente" pós-moderna.

Tratando dessas questões iniciais, destacamos que este artigo é fruto do andamento de duas pesquisas de Doutorado em Educação. Uma dela analisa os discursos sobre currículo e 
gestão em torno do significante "qualidade na/da escola pública", e a outra analisa as políticas de Educação de Jovens e Adultos dos sistemas estaduais de educação no Brasil. Ambas se inserem nas pesquisas desenvolvidas pelo Centro de Estudos e Pesquisas em Administração da Educação (CEPAE).

O CEPAE realiza pesquisas e estudos sobre políticas educacionais com destaque para a gestão escolar e educacional. No momento atual, o grupo vem se debruçando sobre estudos que possam desestabilizar formas cristalizadas de produção do conhecimento lançando mão às discussões pós-críticas em educação. Dentro deste cenário, acreditamos que a obra de Paulo Freire é potente para abrirmos brechas em formas bancárias e excludentes para a efetivação do currículo e da gestão escolar dentro das práticas escolares, bem como na análise de pesquisas dentro desses campos. Nesse sentido, neste artigo, nosso objeto de pesquisa são os construtos teóricos de Paulo Freire nas práticas e pesquisas sobre currículo e gestão escolar dentro do mundo contemporâneo.

Os pensamentos e as perspectivas teóricas metodológicas construídas por Paulo Freire podem contribuir no que se refere à necessidade de abertura em questões tão cristalizadas nos campos do currículo e da gestão escolar no Brasil. Não é de hoje que temos tencionado esses dois campos (mesmo que, em sua maioria, de formas separadas) na proposição de políticas e ações para a escola, como se fossem duas coisas independentes, ou seja, mais uma vez dicotomizando a educação escolar. Exemplo disso é o movimento exacerbado que vem desde as mudanças políticas pedagógicas educacionais no Brasil da década de 1930 até os dias atuais, como destaque nas avaliações externas e mudanças curriculares sinalizadas por Anísio Teixeira (1997), que já preconizavam naquela década e que ainda são fruto de muitos debates atuais como os feitos em torno dos sistemas de avaliação do Brasil, dentre outras.

Paulo Freire foi, sem dúvida alguma, um dos maiores educadores do Brasil. Ele foi/é reconhecido internacionalmente pela sua vasta produção teórica. Não poderíamos deixar de destacar a sua grande atualidade para enfrentar os ataques à democracia que nosso país vem vivenciando nos últimos anos. Consideramos, portanto, toda a sua obra um importante arcabouço teórico metodológico para pensar a educação.

Os pensamentos e as perspectivas teóricas e metodológicas construídas por Paulo Freire podem contribuir com a necessidade de abertura em questões tão cristalizadas nos campos do currículo e da gestão escolar/educacional no Brasil. Sua defesa por uma educação democrática é a esteira para abertura a uma educação de qualidade. Para Paulo Freire, 
a democracia que, antes de ser forma política, é forma de vida, se caracteriza sobretudo por forte dose de transitividade de consciência no comportamento do homem. Transitividade que não nasce e nem se desenvolve a não ser dentro de certas condições em que o homem seja lançado ao debate, ao exame de seus problemas e dos problemas comuns. Em que o homem participe. (FREIRE, 1987, p. 82)

O ato democrático é algo que não se encerra na construção política, mas na própria formação do sujeito, na sua constituição como ser. É interessante o discurso de Freire quando provoca a necessária problematização entre os sujeitos, numa luta em um espaço-tempo que se faz particular e universal. Esse pensamento nos leva a creditar a radicalidade democrática em seu discurso.

O pensamento de Paulo Freire é inovador, criativo, criador, crítico quanto à necessária luta do povo para uma educação de qualidade. Ele não fixa uma posição a qual todos devem seguir. Trata-se de um discurso que abre o jogo político para a luta com adversário, um discurso que permite que os antagonismos sejam cada vez mais potentes no terreno agônico, um discurso que nos evidencia a luta, na ação política, de um sujeito que defendeu/defende que uma gestão escolar/educacional só será de qualidade quando permitir a liberdade, a partir de um currículo que só será de qualidade quanto estiver na busca da prática de liberdade.

O pensamento e ação de Paulo Freire, que se faz democrático, com sapiência de sua limitação, abre possibilidades de pensarmos as potencialidades das negociações entre currículo e gestão escolar/educacional como um movimento político permanente na escola e na educação que rompa com qualquer estagnação de uma única verdade para construção de uma educação de qualidade, pois não interrompe o fluxo de significação construído no contexto educacional. Pelo contrário, abre para que todos possam lutar pela significação daquilo que é qualidade. Entendemos que Paulo Freire não encerra a democracia como ato regulatório e fechado, pois ele aposta que "nós estamos ainda no processo de aprender como fazer democracia. E a luta por ela passa pela luta contra todo tipo de autoritarismo." (FREIRE, 2006, p. 136).

Trata-se de um jogo entre produção de currículo para a efetivação de uma gestão escolar tendo na avaliação externa a criação de patamares de qualidade para a escola. Neste quadro, tanto currículo como gestão escolar são vistos de forma fixas e excludentes, fadados a uma cristalização. Como abrir essa discussão antiga e atual? Vemos em Paulo Freire uma possibilidade profícua de abertura. 
Tanto na gestão escolar quanto nas questões curriculares sempre pairou um ar de suspeita sobre o que a escola possa desenvolver com as suas próprias práticas, fato que levou muitos governos a desenvolverem ações para a escola e não com a escola, de forma a não estabelecer relações com outros “existires". Nesse sentido, lançamos como problema de pesquisa: quais as contribuições do pensamento freiriano que desestabilizam esses engessamentos na área da educação, especificamente aqui no currículo e gestão escolar, abrindo possibilidades de construções coletivas no contexto da escola? Quais pensamentos freirianos podem ser localizados (e não enquadrados) em uma perspectiva pós-moderna progressista/crítica?

O objetivo dentro deste contexto foi analisar, na obra freiriana, concepções teórico-metodológicas que possam contribuir para a abertura de questões curriculares e de gestão escolar na escola pública brasileira, bem como compreender como esses pensamentos abrangem-se e se localizam em uma perspectiva pós-moderna progressista/crítica. Teórico-metodologicamente, operamos com constructos pós-críticos da educação para tentar desestabilizar um ideário fundamentacionalista.

Nesta tentativa, Paulo Freire, em seus últimos livros, levanta a necessidade de se construir novos sentidos para a prática educativa (como, por exemplo, em Pedagogia da Autonomia e Pedagogia da Esperança). Desta feita, acreditamos que outros movimentos teóricos convivem com essa perspectiva, pois não se trata “de um avanço linear, não é uma evolução ou uma superação a supor que os traços do movimento ou da escola de pensamento questionados são apagados" (LOPES, 2013, p. 5). Não rechaçamos a ideia de que outros sujeitos/pesquisadores possam desconstruir o que chamamos de "Paulo Freire pós-moderno crítico". Sendo assim, iremos analisar três obras de Paulo Freire e discutir alguns pensamentos do autor que nos potencializam pensar questões sobre currículo e sobre gestão escolar acerca de uma possível abertura de sentidos e não em torno de uma luta revolucionária unívoca através de suas ideias.

Para tanto, este artigo está dividido em quatro partes: em um primeiro momento, apresentamos alguns pontos teóricos da perspectiva pós-moderna progressista/crítica como referencial; na segunda parte, apresentamos os aspectos metodológicos; na terceira parte, discutimos alguns pensamentos freirianos articulados aos campos do currículo e da gestão escolar; e finalizamos com a conclusão, buscando corroborar com a ampliação do debate sobre as questões apresentadas. 


\section{REFERENCIAL TEÓRICO}

A seguir, são apresentados os referenciais teóricos que respaldam nossas discussões. Na primeira seção, discutimos brevemente a constituição dos campos do currículo e da gestão escolar/educacional; e, na segunda seção, debruçamo-nos na compreensão do terreno pós-moderno crítico, buscando sustentar a presença as obras de Paulo Freire nesse lugar fértil para pensar e fazer currículo e gestões escolares/educacionais.

\subsection{OS CAMPOS DO CURRÍCULO E DA GESTÃO ESCOLAR}

Os estudos em currículo não são tão jovens, e sua institucionalização, seu nome para a constituição como campo, marcado por confluências de elementos contextuais, ficou de forma evidente no cenário educacional, principalmente no início do século passado, com obras de John Dewey e Franklin Bobbit. Desde então, muito se produziu dentro do campo. No Brasil, sinalizamos como um ponto-chave a produção e ação de Anísio Teixeira. Esse estudioso e político brasileiro trouxe, dos seus estudos, nos Estados Unidos, uma nova forma de pensar e fazer currículo no Brasil. Assim, sob forte influência de John Dewey, ele buscou uma escola que se afastasse da repetição excessiva de exercícios e cópias que se centrou a educação brasileira até meados de 1920. A partir deste momento, a tentativa foi a de que o currículo se centrasse no aluno e não nos exercícios. A qualidade da escola articula-se a um currículo que pensa sobre o desenvolvimento do aluno e o seu fazer.

A concepção de currículo vinha principalmente do pensamento de John Dewey, dessa forma, Anísio Teixeira, um dos principais autores brasileiros do início do século passado, defendia a saída de uma escola tradicional "onde os alunos recebem uma tarefa e sofrem uma ordem imposta externamente [...para uma escola nova em que] as matérias são a própria vida" (TEIXEIRA, 1978, p. 47). Esse movimento (ou tentativa de movimento) foi construído em nosso país até meados de 1950, mas não é apagado depois dessa fase.

A partir desse momento, o Brasil começa a pensar e fazer currículos sobre outra forte influência dos Estados Unidos. A obra de Raph Tyler se torna um ícone, um estudo basilar para a construção de práticas curriculares. Dessa vez, sob grande marca tecnicista, o currículo se volta para os objetivos de ensino com foco dado diretamente em como planejar. Assim, a produção intelectual brasileira, bem como as ações governamentais, volta-se para a construção de currículos para as escolas, uma espécie de padronização de currículos para que 
a escola tivesse sucesso em sua empreitada. A escola idealizada era, então, aquela em que todos aprenderiam o mesmo e ao mesmo tempo. Para Tyler (1983), um dos principais autores do pensamento curricular tradicional, o currículo deve buscar atender os objetivos do processo de aprendizagem de forma planificada, mantendo foco também nos conteúdos.

O movimento dos reconceptualistas, iniciado nos Estados Unidos, e a Nova Sociologia da Educação, iniciada na Inglaterra, dão novos contornos aos estudos de currículo no Brasil, a partir de meados da década de 1970. Ademais, a influência marxista e da Escola de Frankfurt dão uma nova guinada na produção intelectual mundial, logo, entram no Brasil com força e, a partir deste momento, há uma produção de crítica aos modelos até então construídos sobre currículo no país. Um ponto-chave na discussão centrou-se no questionamento dos conteúdos, mas não se reduziu a eles. $\mathrm{O}$ foco era na não neutralidade do currículo deste no cenário escolar, o que trouxe ao campo educacional uma grande contribuição, possibilitando questionar a relação do conhecimento e poder.

Após a efervescência de estudos críticos no campo do currículo, começam a emergir no Brasil o que podemos chamar de estudos pós-crítico, os quais, por sua vez, engrossam a crítica à visão tecnicista, ou seja, eles trazem para discussão temáticas ainda pouco discutidas, por exemplo, as questões de sexualidade, gênero, raça, cultura, dentre outros temas potentes para a problematização do campo do currículo. Estes estudos primam por refletir sobre questões até então não tocadas no campo. "Currículo crítico", portanto, é voltado para problematizar o conteúdo, de forma que busque processos emancipatórios e de formação crítica para os alunos (MOREIRA, 1990).

As discussões sobre a diferença cultural, a nosso ver, são um dos pontos fortes da teorização pós-crítica que pode nos ajudar a pensar a qualidade da educação. "Currículo de qualidade" se torna uma demanda no campo, ou seja, pode ser aquele que se insere na disputa, construindo sentidos em torno de se pensar a classe, bem como as questões indígenas, de negros, de gênero, dentre outras temáticas, que são colocadas nas discussões. Para Alice Lopes e Elizabeth Macedo, duas das principais curriculistas brasileiras da atualidade, nesse enfoque do currículo visto no cenário discursivo, tem-se

o entendimento do currículo como prática de significação, como criação ou enunciação de sentidos, torna inócua distinções como currículo formal, vivido, oculto. Qualquer manifestação do currículo, qualquer episódio curricular, é a mesma coisa: a produção de sentidos. Seja escrito, falado, velado, o currículo é um texto que tenta direcionar o leitor, mas que o faz apenas parcialmente (LOPES; MACEDO, 2011, p. 42). 
A gestão escolar/educacional também apresenta uma trajetória marcada por luta em torno de sentidos de qualidade para a educação/escola. Vale destacar, mais uma vez, o pioneirismo de Anísio Teixeira. Da mesma forma que sinalizamos o início da efervescência dos estudos curriculares no Brasil com a sua produção, reiteramos a sua importância para os estudos em gestão escolar/educacional. Destacando a importância do gestor escolar em ser um professor, o educador inaugura uma concepção de gestão escolar/educacional com características próprias, refutando a forte influência dos estudos da Teoria Geral da Administração no campo educacional, principalmente nos anos 1960, década em que foi criada a Associação Nacional de Professores de Administração Escolar (ANPAE).

Mesmo com tal visão muito potente, a produção brasileira sobre gestão escolar/educacional manteve um jogo de disputa acerca dos sentidos sobre por onde deveria caminhar o campo. Com influência dos estudos da Teoria Geral da Administração e do funcionalismo, pragmatismo, psicologismo, os estudos e produção do campo centraram-se em como fazer a organização escolar funcionar bem como uma empresa funciona. Este movimento teve muita força no Brasil até o final da década de 1970, e essa fase foi marcada por uma visão empresarial e tecnicista. José Querino Ribeiro, um dos maiores representantes deste movimento, busca sintetizar o que ele compreende por atividades específicas da Administração, como aquelas de "planejamento, organização, assistência à execução, medida ou avaliação dos resultados e relatório crítico" (RIBEIRO, 1953, p. 119), ou seja, meios técnicos para garantir a efetividade das políticas para a escola.

Assim como no campo do currículo, a década de 1980 teve uma guinada para os estudos críticos em gestão escolar/educacional. Os estudos marxistas foram basilares para a formação de uma nova comunidade epistêmica no campo. Dessa forma, a produção girou em torno do combate à gestão empresarial, por uma escola para a classe trabalhadora. Este grupo de teóricos da gestão escolar/educacional, tais como Maria de Fátima Costa Félix (1984) e Vitor Henrique Paro (1986), dentre outros, que teve uma grande contribuição para o campo da gestão escolar/educacional, afirmou a especificidade da escola quando falamos de gestão escolar/educacional, isto é, defendeu que a escola não é uma empresa e, nesse sentido, não cabe uma gestão pautada em aspectos que preveem a produção em série, a fim de que se tenha sucesso, para que a escola seja de qualidade. 
A partir do final da década de 1980, quando a gestão escolar/educacional ancorou-se ao significante "democracia", ou, mais especificamente, à gestão democrática, aparentemente, há uma espécie de fixação teórica no campo quanto ao que ao conceito de gestão escolar/educacional. Não queremos dizer que não houve ou não há produção de grande importância para o país no campo, mas que, do ponto de vista teórico, não saímos da discussão entre a visão tecnicista empresarial e a visão da especificidade da escola, ou seja, há muita produtividade no campo, mas a lógica permanece em torno de que há ou não há gestão democrática.

Com a produção do CEPAE, podemos dizer que um dos pontos de entrave para o desenvolvimento do campo seja justamente tal binarismo e fixação em dizer se na escola ou na educação há gestão democrática ou não. Aspectos democráticos são fundamentais para a educação e para a escola, contudo, a nosso ver, não conseguimos avançar no campo da gestão escolar/educacional se não tentarmos buscar outras formas de fazer gestão, outras formas de compreender as possibilidades democráticas. Sinalizamos aqui o não avanço teórico do campo no tocante a investigar, pensar, fazer, ter outros modos de gestão escolar/educacional.

Desse modo, o que encontramos no campo depois deste momento são estudos que não se dedicam a pensar/avançar a gestão escolar/educacional do ponto de vista teórico conceitual, e, dessa forma, hegemonizam os sentidos de sua ação (da gestão) como "meio", o que, a nosso ver, pode fragilizar o campo. A fragilidade não se encontra na ausência de estudos e também na qualidade das pesquisas desenvolvidas, mas na ausência de perspectivas contrapostas que possam fazer o campo da gestão escolar/educacional ser pensada de outras formas.

Aproximadamente de 1990 até os dias atuais, nos estudos e pesquisas do CEPAE, encontramos um grande volume de pesquisas e trabalhos voltados a entender temáticas que se relacionam com a gestão escolar/educacional, tais como: financiamento da educação, políticas governamentais, conselhos escolares, avaliação em larga escala, dentre outros, todos esses temas importantes para o campo da gestão escolar/educacional. Isso significa dizer que a concepção acerca da gestão escolar/educacional ainda permanece como "meio" para se atingir algo. Reiteramos, a partir dessas questões, a importância da produção no campo e de seus teóricos para a educação brasileira, contudo, a gestão escolar/educacional permanece desta forma sob uma visão secundária à política, à filosofia ou à didática. 
Por isso, é importante, como problematização deste artigo, a possibilidade de pensar currículo e gestão escolar/educacional com sentido que pode permitir a desconstrução de possíveis hierarquias entre os dois campos, bem como a potencialidade para a educação escolar pública de qualidade, fundamentalmente a partir do pensamento freiriano.

\subsection{O PENSAMENTO PÓS-MODERNO: UM LUGAR PARA PENSAR PAULO FREIRE?}

Um alerta será necessário já na abertura deste artigo: não pretendemos enquadrar a obra de Paulo Freire dentro do movimento pós-moderno e de nenhum outro, pois acreditamos que suas contribuições para a educação vão além de qualquer categorização epistemológica. $O$ que nos colocamos a problematizar é a sua potencialidade em questões educacionais (aqui currículo e gestão escolar) no mundo pós-moderno marcado pela velocidade de relações e de múltiplas demandas que circunscrevem a organização social.

A intenção aqui é a de tentar ampliar as potencialidades dos pensamentos freirianos aos campos do currículo e da gestão escolar, identificando e problematizando algumas questões que estão intimamente ligadas aos sentidos de abertura e flexionamento ao agirmos com a escola pública e não simplesmente para ela. Trata-se de pensar Paulo Freire em um terreno fértil para pensar os descentramentos dos sujeitos, logo, pensar seus inacabamentos permanentes em uma constituição social que não está fadada a ter um pensamento único e sim um pensamento não definitivo, haja vista que estamos sendo no mundo, logo se pode ter possibilidades de lutas na/pela diferença.

Nesse sentido, é preciso compreender o que é o pós-modernismo para então problematizarmos o terreno pós-moderno crítico. O pós-modernismo não se configura como um conceito, ou linha de pensamento de consenso entre os pesquisadores que se debruçaram sobre ele. Para tanto, para entender o pós-modernismo, devemos voltar o olhar para o modernismo, para o qual "pode ser visto, na filosofia, como um movimento baseado na crença no avanço do conhecimento, desenvolvido a partir da experiência e por meio do método científico" (PETERS, 2000, p. 13). O que pretendeu no modernismo foi a tentativa de totalização do conhecimento, recorrendo à proliferação de grandes metanarrativas.

Lyotard (1989, p. 34) propõe que dialética do espírito, a hermenêutica do sentido, a emancipação do sujeito racional ou trabalhador, o desenvolvimento da riqueza, decide se chamar "moderna" a ciência que a isto se refere para se legitimar (LYOTARD, 1989, p. 34). 
A tentativa do modernismo era a de buscar o fechamento do fluxo contínuo da formação humana, a busca por uma totalização igualitária para todos os sujeitos. O pós-modernismo rechaçou exatamente esse movimento, mostrando a precariedade da constituição social, da clausura de pensar e fazer todos os sujeitos centrados.

Nesse sentido, o pós-modernismo busca problematizar a diferença, o difuso, o fugidio, as vidas dos sujeitos e suas andanças. O pós-modernismo questiona as tentativas de cristalizar o pensamento e o conhecimento como único e verdadeiro. Contudo, é preciso compreender que uma visão simplista sobre o pós-modernismo pode levar a análises vazias e sem sentido. Por isso, a nosso ver, é preciso olhar para o pós-modernismo de forma crítica e responsável, e é deste lugar que localizamos Paulo Freire.

Assim, distinguimos logo de entrada que acreditamos em uma perspectiva pós-moderna progressista/crítica e não celebratória. Há uma distinção necessária nesse cenário, a qual bem sinaliza Santos (1999, p. 214): “o pós-moderno celebratório reduz a transformação social à repetição acelerada do presente e se recusa a distinguir entre versões emancipatórias e progressistas de hibridações e versões regulatórias e conservadoras", ou seja, não há uma tentativa de mudança no status quo das destruições sociais que assolam o mundo. Já o pós-moderno de oposição (crítico) questiona qualquer ideia fechada de libertação e uma sociedade melhor é seu permanente alvo. Busca-se nele uma democracia radical que se preocupa com a luta pela/na diferença eliminando qualquer forma fundacional de sociedade (SANTOS, 1999). É assim que encaramos a atualidade do pensamento de Paulo Freire: questionadora de ideias fechadas para a libertação dos sujeitos, um pensamento úmido que adentra das discussões e práticas em nossa atualidade.

Localiza-se Paulo Freire nesse cenário por acreditar que ele busca incessantemente a construção do conhecimento de emancipação, que nos evidencia a liberdade do conhecimento, fugindo de conhecimentos plenos e garantidores da evolução do ser humano. Como sinaliza Santos (1999), o pensamento pós-moderno crítico é assim chamado por ter um compromisso e criticar a própria forma de construção de conhecimento, buscando na marginalidade a construção de conhecimentos emancipatórios em que conhecer é reconhecer o outro. Segue Santos (1999) dizendo que

conhecer é reconhecer, é progredir no sentido de elevar o outro da condição de objecto à condição de sujeito. Esse conhecimento-reconhecimento é o que designo 
de solidariedade. Estamos tão habituados a conceber o conhecimento como um princípio de ordem sobre as coisas e sobre os outros que é difícil imaginar uma forma de conhecimento que funcione como princípio de solidariedade (SANTOS, 1999, p. 205).

Embora alguns discursos no âmbito da pesquisa em educação no Brasil insistam em afirmar que Paulo Freire foi um marxista, devido a sua luta incessante pela libertação do povo, não o enquadramos em tal perspectiva, e, pelo contrário, distanciamo-lo desse movimento no momento em que podemos ver em suas obras uma abertura à construção de microrrevoluções sociais em torno de lutas marcadas pela diferença, pela legitimidade do conhecimento solidário, que compreende as coisas e os outros nos seus tempos e espaços de permanente construção.

Para Santos (1999), no pensamento pós-moderno crítico, o conhecimento deve ser contextualizado a partir da vida das pessoas, progredindo quando transforma sem sentido progressista, ou seja, é um conhecimento que se conquista prudentemente na sociedade, justamente o que é preconizado nas obras de Paulo Freire.

Por isso, sinaliza-se que Paulo Freire apresenta, em suas obras, pensamentos teórico-metodológicos potentes que nos permitem pensar a luta democrática radical no contexto atual dentro do que Boaventura de Souza Santos chama de "pensamento pós-moderno crítico", isto é, trata-se de pensamentos potentes para provocarem mudanças num tempo em que as relações dos sujeitos com os objetos e dos sujeitos com os sujeitos são cotidianamente marcadas pelas mudanças deste tempo dito pós-moderno.

A partir dessa discussão acerca da atualidade do pensamento de Paulo Freire dentro do contexto pós-moderno progressista/crítico, iremos, a seguir, discutir alguns dos seus conceitos/pensamentos que são, a nosso ver, ancorados no tempo atual e são potentes para pensar práticas e pesquisas sobre currículo e gestão escolar:

a) Inacabamento: conceito primeiro (a nosso ver) que preconiza o pensamento freiriano, evidencia o nosso "ser" humano e o nosso "estar sendo" no mundo, sinaliza a nossa condição inconclusa e nos afirma que justamente por essa condição inacabadamente humana, já que podemos ser mais em qualquer tempo, contexto e lugar;

b) Emancipação: revela a nossa condição de inacabamento e diz respeito a colocar os homens e mulheres no caminho do permitir o vir a ser, permissão não dada, mas construída incessantemente, resultando numa capacidade de não adaptação e sim 
de integração à realidade acrescida da possibilidade de transformá-la, supondo uma opção, cuja nota fundamental é a criticidade;

c) Práxis: processo fundamental para a emancipação que se mostra na capacidade de inserção crítica na realidade. Consiste em admirar o mundo para subjetivamente objetivá-lo, implicando a ação e a reflexão sobre si e sobre o mundo para transformá-lo, entendendo que essas transformações não são fixas justamente porque o tempo histórico está sendo feito pelos homens e mulheres, no "inédito viável" de serem sujeitos de sua própria história;

d) Democracia Radical: Freire nos chama a atenção para a indignação, para intolerância, fazendo-nos um convite ao diálogo em oposição às relações verticalizadas, contudo, não resume a democracia a um consenso de ideias, tão somente à luta de classes, mas advoga que as relações de poder são atravessadas pelos novos meios culturais de massa. Neste cenário, então, a educação e a pedagogia são fundamentais para se construir a radicalidade a quaisquer formas de opressão;

e) Tema Gerador: não se designa como um método de alfabetização. Paulo Freire pensou uma ação metodológica encharcada de teoria interdisciplinar. Parte da realidade dos homens e mulheres, para, no coletivo, construírem a suas teorias, capazes de desvelar a realidade presente e propiciar a práxis para transformá-la.

Tais conceitos/pensamentos assentam na luta contra um movimento pós-moderno celebratório e evidenciam uma ruptura com qualquer estabilidade pretendida. Elas não abandonam a luta pelas questões sociais e por uma liberdade pretendida aos sujeitos, mas sim ampliam as possibilidades dos sujeitos serem mais em sua complexidade e diferença.

É como sinaliza Laclau (1991) quando aborda a questão da fronteira estabelecida (tentativa de estabelecimento) entre o moderno e pós-moderno dizendo que não há um abandono das questões modernas, mas sim sua reconfiguração, uma abertura, e, caso haja essa ideia de rechaçamento total do outro, o pós-moderno crítico será um novo movimento estático e monolítico centrado em seus desejos próprios e não das diferenças dos sujeitos, por isso existe proficuidade ao provocar uma ruptura naquilo que se vê como fundacional e não apagar de uma vez por todas aquilo que se quer em outras visões. 


\section{Seção: Currículo - Artigo original}

14

A obra de Paulo Freire revela suas permanentes mudanças, sempre aberto às experiências e ao viver em variados lugares e contextos, ou seja, a história como possibilidades. Seus escritos nos evidenciam a sua condição de ser inconcluso e extremamente esperanço, permitindo-nos compreender as múltiplas/plurais realidades.

A seguir, apresentamos a análise realizada nas obras selecionadas cotejando o campo do currículo e da gestão escolar. Tencionamos os conceitos e pensamentos de Paulo Freire para alargar a leitura dos campos do currículo e gestão escolar.

\section{METODOLOGIA}

A pesquisa realizada teve o corte qualitativo, ou seja, buscamos manter um contato direto com o objeto de estudo, descrevendo os dados, mantendo a preocupação com o processo de construção discursiva (LÜDKE; ANDRÉ, 1986). O tipo do estudo foi do tipo exploratório, descritivo e bibliográfico, que segundo Gil (2002), consiste em descobertas intuitivas a partir dos documentos/livros analisados. Como salienta esse autor, a vantagem da pesquisa bibliográfica "reside no fato de permitir ao investigador a cobertura de uma gama de fenômenos" (GIL, 2002, p. 45).

Os dados foram organizados tomando por base três obras de Paulo Freire: A educação na cidade, Pedagogia do Oprimido e Pedagogia da Autonomia. A análise dos discursos que constituem as três obras selecionadas foi feita operando com alguns conceitos da Teoria do Discurso de Ernesto Laclau e Chantal Mouffe (2011).

Nosso referencial metodológico está inscrito nos estudos pós-estruturais. Ancoramo-nos em alguns conceitos da Teoria do Discurso, proposta inicialmente por Ernesto Laclau e Chantal Mouffe na obra Hegemonia e estratégia socialista: por uma democracia radical e plural, publicada em 1985. Os autores realizam um processo de desconstrução derridiana, dos sentidos de hegemonia propostos por autores marxistas, notadamente a partir das noções de articulação e hegemonia de Antônio Gramsci. Assim, o discurso torna-se o constitutivo de todas as relações sociais. Podemos, então, a partir do arcabouço teórico-metodológico construído pelos autores, compreender a constituição das articulações sociais como uma construção discursiva.

A Teoria do Discurso rompe com a noção fundacional, positivista e moderna de ciência, perspectivas criticadas pelo "falso" idealismo a partir dos relativismos. Os autores entendem que toda realidade é uma produção discursiva, problematizam as contingências da 


\section{Seção: Currículo - Artigo original}

vida humana, não em um sentido de extrair do campo empírico uma verdade, mas de compreender como as práticas discursivas constituem tal realidade, marcada pela precariedade, fruto do discurso. A Teoria do Discurso busca compreender o problema e não dizer como resolvê-lo de uma forma pré-estabelecida para o sucesso, "dessedimentando" o que está naturalizado.

As nossas estratégias, a partir da Teoria do Discurso, buscam fugir e refutar um $a$ priori. Dessa maneira, podemos sinalizar que os objetos, a educação, o currículo, a gestão e a qualidade são construídos no contexto discursivo de forma provisória, posta em jogos de linguagem. Não pretendemos buscar explicações gerais, comparativas e explicativas de uma verdade absoluta. O jogo é o que acaba com a estrutura centrada, uma vez que nele se permitem as aberturas possíveis, desestabilizando qualquer tentativa de significação plena (DERRIDA, 1971), por isso, o discurso que pode vir a constituir o que seja currículo e gestão escolar/educacional será uma construção no jogo, no jogo político, no indeterminado. Dito de outro modo, buscamos compreender as hegemonias construídas nos campos, bem como tentar evidenciar possibilidades de algumas aberturas para pensarmos em outros modos de fazer pesquisa nos dois campos a partir das suas negociações.

Colocando-nos a partir desse referencial metodológico, anunciamos a nossa própria precariedade e limitação, uma vez que estamos no jogo discursivo, porém, um horizonte é preciso ser construído, um horizonte inalcançável de uma busca incessante por significação. A precariedade nos coloca no terreno da insuficiência contínua de estabilização de algo, mostra o quanto estamos na limitação de construções que podem ser tomadas como verdadeiras e únicas. Tal precariedade e limitação são caminhos que buscamos traçar, pois, ao próprio leitor, caberá a construção de outros textos, ou seja, a partir da sua leitura, outros textos poderão ser construídos.

Queremos dizer com este pensamento que algumas hegemonizações serão estabelecidas em torno do que acreditamos ser possível de construção para uma escola pública de qualidade a partir das articulações entre os campos do currículo e da gestão escolar/educacional, e aqui reside a nossa precariedade, nossa limitação, pois buscamos um horizonte impossível. Rastros de uma produção discursiva que trazem em suas trajetórias significações de significações, as quais são marcadas por rastros dos rastros de que ela se constituiu, sem ter uma origem (DERRIDA, 2001, 2004). Assim, lançamo-nos ao mar da 


\section{Seção: Currículo - Artigo original}

16

significação da qualidade nos rastros dos rastros que os campos do currículo e da gestão escolar/educacional puderam construir, nos discursos de alguns autores clássicos dos campos.

A Teoria do Discurso nos evidencia, por meio de sua rede conceitual, o quão arenoso é o terreno educacional. Marcada por sentidos que se articulam para entendimento da hegemonização do que venha a ser currículo e gestão escolar/educacional, tal rede se faz de forma a entendermos que o vir a ser se constitui nas pulsões dos sujeitos, as quais se modificam constantemente. O "discurso" é aquilo que constitui todas as realidades possíveis, sendo a sua compreensão possível a partir do que significa a "prática articulatória". A partir desses dois pontos, mobilizamos outros para compreender como os campos do currículo e da gestão escolar/educacional se constituíram no Brasil e quais as contribuições das negociações desses dois campos para a qualidade da educação pública.

Para Laclau e Mouffe (2011), “discurso" é o que constitui toda a ação social. Os autores não limitam discurso à junção de textos e palavras, ao dito e ao escrito. É discursivamente que sabemos o que é uma mesa, uma lousa, ou uma política de currículo ou de gestão escolar/educacional; que construímos o que é um lar ou um presídio, uma escola ou uma senzala, uma rua ou uma pista. Não há nada que escapa ao discurso. O que a escola faz de currículo e de gestão escolar/educacional é uma construção discursiva.

Contudo, para que haja tal construção, é preciso que existam "articulações", as quais são construídas entre os significantes, gerando diferentes significações. Segundo Laclau e Mouffe (2011), a "articulação" é construída por elementos que se tornam momentos, o resultado destes momentos são os discursos provisoriamente hegemonizados. Ao que venha a ser "currículo" ou "gestão escolar/educacional" dependerá das articulações feitas entre múltiplos elementos, sendo o momento que tais elementos - marcados por diferenças e antagonismos - que se estabelece a significação provisória dos campos de currículo e gestão escolar/educacional, ou seja, são construídos discursivamente. Essa dependência é marcada pela disputa entre adversários, que lutam no terreno agonístico, como apresenta Mouffe (2011).

Nesse cenário, os autores lançam mão de como os sujeitos são instáveis devido às marcas das "diferenças", bem como marcados pelos momentos políticos que a significação provoca a "equivalência", o que gera as posições incertas. Nos campos do currículo e gestão escolar/educacional, existem formas diferentes de significação que provocam as eternas negociações no campo discursivo. Ao longo da história do Brasil, o currículo assumiu e vem 
assumindo múltiplos sentidos, obras, autores, políticas governamentais e os sujeitos da escola indicam várias formas de compreensão do que venha ser sua prática curricular. Da mesma forma, o campo da gestão escolar/educacional também vem assumindo múltiplas posições acerca do que significa gestar uma escola ou a educação.

O jogo discursivo marcado pelos significantes nos constrói enquanto sujeitos que deslizam nas construções realizadas nos jogos entre a diferença e a equivalência. Não somos sujeitos em uma completa e infinita diferença, mas criamos em nossas trajetórias muitos momentos de estabilidade precária ao que pensamos e desejamos. Das negociações provocadas pelas significações as diferenças, muitas vezes, apagam-se e, contingencialmente, tornam-se em equivalências. Nesse jogo de apagamento provisório do discurso que se estabelece precário e contingencialmente sobre as nossas realidades, podemos ser levados a pensar/fazer currículos e gestões, dessa maneira, igualamo-nos provisoriamente em torno de algumas posições que acreditamos como certas ou as melhores.

Dentro desse jogo para a compreensão das relações sociais, logo também das relações no campo do currículo e da gestão escolar, encontramo-nos na luta antagônica. É o corte antagônico que nos propulsiona para uma possibilidade democrática de pensarmos o que queremos construir de qualidade para a escola pública. Não pensamos igual a todo o momento e é por isso que o antagônico é um elemento importante para a construção de práticas democráticas no contexto escolar.

As relações antagônicas, na constituição social, estabelecem que não há fim de uma totalidade discursiva, promovendo que sujeitos estejam a todo o momento criando outras negociações. Laclau e Mouffe (2011) estabelecem que os jogos antagônicos não podem ser eliminados, uma vez que vamos construir posições sobre os sentidos que queremos dar ao mundo no conflito, ou, como Mouffe $(1996,2011)$ nos coloca, um consenso conflituoso, em que o conflito permanece dentro de um espaço tempo harmonioso provisório, cheio de possibilidade de negociações. O antagonismo deve ser transformado em uma luta agônica, ou seja, o sujeito não eliminará o outro, pois o verá como seu adversário e não como inimigo.

Como já dito, os campos do currículo e da gestão escolar/educacional passaram e passam por múltiplas formas de significação. Sujeitos lutam para significar currículo e gestão escolar/educacional a fim de que estes sejam as melhores e mais profícuas formas de se pensar e fazer. As construções sociais em torno destes campos educacionais são marcadas por disputas de sentidos dentro de uma arena extremamente conflituosa. Este espaço-tempo é 
fundamental para pensarmos democraticamente o que é currículo e gestão escolar/educacional. É nesse momento, nas construções discursivas, que nos posicionamos para promover aquilo que acreditamos como sendo a melhor opção.

Aquilo que o sujeito deseja ser ou fazer sempre estará dentro de jogos de linguagens com o outro. O outro o constitui. É por meio desse outro que o sujeito constrói as suas práticas discursivas. Portanto, não pode eliminar os antagonismos, porque é possível transformá-los em potencialidades para um mundo mais justo. É com ele que podemos ter currículos e gestões escolares/educacionais mais justos na escola. É neste espaço-tempo que podemos construir significações provisórias, marcadas de possibilidades de vir a ser, pululando momentos democráticos.

Este momento de estabilizações provisórias, de universalização de um sentido acontece na constituição de "significantes vazios". Segundo Laclau (2011), um significante vazio é a plenitude de sua não significação, é o momento de aglutinação de sentidos de um significante ao ponto deste não conseguir ter uma significação plena. Assim, podemos entender como acontecem as estabilizações discursivas. Elas nos evidenciam como fora construída toda uma cadeia discursiva.

Nos campos do currículo e gestão escolar/educacional, podemos analisar a produção de múltiplos significados, dados em diversos momentos, por diversos sujeitos. Concepções de currículo como conteúdo, cultura, política, objetivos, dentre outras significações, já foram construídas na história da educação brasileira. Concepções de Gestão como mediação, administração de recursos, gestão democrática, dentre outras significações, já foram construídas na história da educação brasileira. Contudo, esses e outros significantes são o que dão sentido às práticas escolares, às construções de políticas na escola.

É dessa forma que chegamos à hegemonização provisória, momento em que o dado sentido é provisoriamente estabilizado, fechado, em que uma particularidade encarna uma universalidade marcada por contínuas disputas. É neste momento que chegamos, segundo os autores, a um "ponto nodal", que é o momento em que os processos de significação fecham para que a particularidade seja universalizada, criando, assim, um significante vazio. Trata-se de um ponto em que se fecha uma cadeia discursiva, que hegemonizamos discursivamente a concepção de currículo e gestão escolar/educacional, por exemplo. Porém, dadas as múltiplas articulações que não se acabam neste momento, a produção de currículo e gestão escolar/educacional pode ser mudada a qualquer momento, criando outras formas de 
compreendê-los e fazê-los. Reside nesse instante um processo altamente democrático, ao qual Laclau e Mouffe (2011) chamam de "democracia radical e plural".

A democracia radical e plural possibilita que demandas diversas atravessem a constituição de políticas, uma vez que nela podemos ver radicalmente a pluralidade que lançam as liberdades entre os sujeitos. Esse movimento permite criar articulações entre currículo e gestão escolar/educacional de forma que construam em múltiplos espaços, tempos e qualidades para a educação pública. Há nesse jogo a potencialização para a democratização (LACLAU; MOUFFE, 2011). Assim, a democracia não será garantida apenas com eleição de diretores ou a construção de uma proposta curricular feita pelo governo, dentre outros aparatos, mas sim nas articulações que os sujeitos da escola estabelecem dentro da pluralidade de posições.

Isso se deve pela constituição dos sujeitos. Somos constituídos por identidades provisórias, marcadas pelos antagonismos, pelas diferenças. Somos sujeitos da política no jogo político na escola, por isso, indetermináveis e inseridos no terreno indecidível. Dessa forma, entendemos currículo e gestão escolar/educacional em um movimento por vir a ser. Não existe uma ideia finalística. Currículo e gestão não serão algo fixo como temos visto em algumas perspectivas. A construção discursiva sempre será marcada por articulações provisórias.

Assim, partimos da construção do currículo e gestão escolar/educacional como escritura, com a desconstrução de verdades absolutas, de fixações, ou seja, o que as possíveis leituras potencializam e/ou bloqueiam, o que é privilegiado e o que é negligenciado. A escritura e suas textualidades se constroem no contexto político, assim, currículo e gestão são vistos aqui como textos políticos, dentro do jogo antagônico que privilegia a produção dentro de uma arena política.

A visão de provisoriedade política no jogo político vem do entendimento dos campos como escritura, como algo que não se pode fixar em um único sentido; não há essência; os campos se potencializando à qualidade a partir de "brisuras", aberturas, visíveis e invisíveis; isso por sermos sujeitos que se movem de modo constante, construídos permanentemente por processos de significação, com decisões precárias e contingentes.

As discussões realizadas por nós, pesquisadores, durante a análise de algumas obras clássicas serão marcadas pelas desconstruções, que, por sua vez, se constituem com rastros 
dos rastros (DERRIDA, 2004). Sendo assim, o trabalho crítico permite uma não fixação de sentidos, sendo o leitor deste artigo convidado à realização de novas/outras leituras.

\section{RESULTADOS E ANÁLISE}

A intenção apresentada neste artigo é a de problematizar e evidenciar o quanto a obra de Paulo Freire é importante para pensarmos a educação no Brasil. Destacamos que nosso objeto aqui são alguns dos pensamentos freirianos, presentes em algumas de suas obras. Sabemos que a obra de Paulo Freire é muito maior ao que apresentamos aqui, mas temos o desejo de sinalizar que, em poucas obras, encontramos uma infinitude de possibilidades para boas práticas pedagógicas na/da escola. Nosso objetivo foi analisar concepções pedagógicas que possam contribuir para a abertura de questões curriculares e de gestão escolar na obra de Paulo Freire, bem como compreender como esses pensamentos podem se localizar em uma perspectiva pós-moderna crítica.

Com o olhar direcionado para este objetivo, buscamos realizar a leitura minuciosa de conceitos presentes principalmente em três obras de Paulo Freire: A educação na cidade (1991), Pedagogia do Oprimido (1987) e Pedagogia da Autonomia (2002). Didaticamente, os conceitos estão separados, contudo, é notório que o pensamento de Paulo Freire atravessa toda a sua obra. Concorda-se com Lima e Mioto (2007) quando sinalizam que a pesquisa bibliográfica é fundamental para a ampliação de conceitos importantes no que se refere à compreensão do objeto da pesquisa.

Sinalizam-se aqui alguns conceitos freirianos e suas relações para com o que estamos chamando de "pensamento pós-moderno crítico". A ideia da análise é evidenciar que alguns conceitos/pensamentos freirianos estão ligados a um pensamento aberto e flexível. Apresenta-se e discute-se tais pontos refletir acerca de um pensador brasileiro que tem contribuições gigantescas para a construção de uma escola pública de qualidade.

As contribuições do pensamento de Freire vão a largos passos ajudar a pensar as nossas pesquisas sobre educação e a proposição de práticas pedagógicas em/com a escola aqui sinalizadas a partir do campo do currículo e da gestão escolar, a fim de continuar a pensar práticas pedagógicas libertadoras, mesmo que essa liberdade seja provisória e contingente, em um eterno vir a ser.

A seguir, serão apresentadas três seções que problematizam o pensamento freiriano quanto aos sentidos de currículo e gestão escolar, evidenciando como os seus conceitos são 
potentes para pensarmos e fazermos a educação dentro de um terreno pós-moderno crítico. As análises discursivas dos resultados giram em torno dos sentidos de democrática radical, ou seja, uma forma não linear e fixa de pensar a democracia, dos temas geradores como construções curriculares em um movimento de reconhecimento do conhecimento dos sujeitos em seus múltiplos espaços tempos de vidas e a emancipação como inacabamento, ou seja, a emancipação como horizonte a ser buscado.

\subsection{DEMOCRACIA RADICAL: POR UMA GESTÃO ESCOLAR DEMOCRATIZADA}

A Educação na cidade (1991) é uma obra que apresenta algumas entrevistas cedidas por Paulo Freire quando ele estava frente a Secretaria de Educação do município de São Paulo. Ele faz uma reflexão sobre a sua prática como político dentro de um cenário de democratização da escola pública.

Paulo Freire, na função de Secretário de Educação, promove coletivamente uma mudança radical na gestão escolar. Propõe coletivamente uma efetiva gestão democrática quanto à participação de autonomia da escola. Nessa obra, Paulo Freire evidencia em sua ação que as decisões e mudanças no cenário educativo são democráticas no momento em que os sujeitos decidem os rumos políticos pedagógicos do espaço-tempo em que estão inseridos. Há nesse movimento uma ação democrática que não serve apenas para decidir sobre algo que já está pronto, mas, além disso, torna uma ação e propõe a luta pelas micro revoluções em cada escola.

Aqui reside um conceito muito interessante quanto à posição pós-moderna crítica em Paulo Freire. Podemos perceber que os sentidos democráticos são abertos. Há uma radicalidade nos sentidos democráticos na gestão de uma escola. A decisão não é do Diretor e nem do Secretário de Educação, mas sim da coletividade. Podemos perceber a luta na diferença da posição de cada sujeito político. Essa posição nos mostra o quão potente é a proposição freiriana para pensarmos a democracia.

Nessa gestão democrática radical, é fincada a ideia de currículo inter e transdisciplinar construído no coletivo da escola, fato que fica longe da ideia de um currículo único para todas as escolas. Aqui, mais uma vez, podemos perceber a posição pós-crítica do autor quando vislumbra dentro de uma democracia radical a existência de uma prática curricular que vai além de propositura de conteúdos gerais a todos os alunos, bem como a decisão sobre a 
organização da escola longe de ser uma posição do diretor(a) escolar, mas sim de todos os sujeitos. Como podemos ver a seguir:

a reformulação do currículo não pode ser algo feito, elaborado, pensado por uma dúzia de iluminados cujos resultados finais são encaminhados em forma de 'pacotes' para serem executados de acordo ainda com as instruções e guias igualmente elaborados pelos iluminados. A reformulação do currículo é sempre um processo político-pedagógico e, para nós, substantivamente democrático. (FREIRE, 2006, p. 24)

Isso nos permite pensar nas relações sempre inacabadas e marcadas por lutas antagônicas na efetivação do currículo na escola, mostrando que o movimento democrático radicalizado é espaço tempo de negociações entre os viventes na escola.

No cenário de pesquisas, operar com o conceito de democracia radical freiriano permite rechaçar ideias de uma verdade absoluta e que existe um único modelo de democracia. Também permite pensar que a democracia acontece de múltiplas formas na escola, afastando as análises pautadas na fundamentação de que a escola não faz gestão democrática, uma vez que não a efetiva através de instrumentos pré-estabelecidos para a efetivação democrática, como, por exemplo, os conselhos escolares. A democracia para Paulo Freire é construída no coletivo, nas disputas, e, sendo assim, não podemos prescrever um modelo único.

Acreditamos que este conceito/pensamento de democracia radical abre e alarga a possibilidade de feitura de gestão democrática na escola, bem como propicia a construção de currículo em um movimento dialógico e inacabado de um vir a ser cotidiano. Além disso, permite que pesquisas no campo do currículo e gestão problematizem mais os movimentos democráticos do que tentem prescrever o que e como a escola pública deva proceder.

A rigorosa defesa para uma educação democrática potencializa a criação de um espaço tempo de negociações entre currículo e gestão escolar/educacional, pois abre para a luta entre os sujeitos. Como o próprio autor esclarece, há nesse ponto

a necessidade de uma educação corajosa, que enfrentasse a discussão com o homem comum, de seu direito àquela participação. De uma educação que levasse o homem a uma nova postura diante dos problemas de seu tempo e de seu espaço. A da intimidade com eles. A da pesquisa ao invés da mera, perigosa e enfadonha repetição de trechos e de afirmações desconectadas das suas condições mesmas de vida. A educação do "eu me maravilho" e não apenas do "eu fabrico". (FREIRE, 1987, p. 93). 
A democracia defendida pelo autor nos leva ao terreno do incerto, do provisório, da incessante busca por mudança para a defesa de uma educação de qualidade. Diante dos nossos problemas acerca da construção curricular, podemos lutar em torno do que possa ser melhor para a educação de qualidade. Frente os nossos problemas acerca da construção gestora, podemos lutar em torno do que possa ser melhor para a educação de qualidade. É possível, para além de pensar de forma polarizada, problematizar a educação de qualidade dentro de uma política cultural da escola, a qual permite a negociação permanente entre as demandas de currículo e gestão escolar/educacional, qual sejam, um currículo fugidio da enfadonha repetição e afirmação desconectada da vida e uma gestão escolar/educacional que enfrente coletivamente os problemas vivenciados no seu espaço-tempo.

Podemos ver na obra freiriana uma radicalidade capaz de encetar uma democracia que não será garantida apenas com eleição de diretores ou a construção de uma proposta curricular feita pelo governo, dentre outros aparatos, mas sim nas articulações que os sujeitos da escola estabelecem dentro da pluralidade de posições, ou seja, um pensamento crítico que não permite a totalização e o fechamento de posições democráticas, garantindo justamente a abertura para o permanente debate na luta pela justiça.

\subsection{TEMAS GERADORES: MOVIMENTO DE “VIR A SER CURRÍCULO”}

Em Pedagogia do oprimido (1987), exilado do país, Paulo Freire escreve sobre a opressão do povo, dentre outros pontos, com destaque para a discussão sobre libertação, dialogicidade, educação bancária e temas geradores.

O diálogo e o sujeito inconcluso são bases nesta obra para a construção de um currículo escolar que emerge no/do/com o cotidiano escolar. Não há amarras para a efetivação do currículo. Os temas geradores, base para a construção curricular, não são conteúdos dados a priori. Eles são construídos coletivamente e através de um permanente diálogo horizontal.

Contrário a um currículo prescritivo, Paulo Freire apresenta a construção do processo de aprendizagem em um movimento de "vir a ser currículo" no contexto escolar. Aqui não há uma ação prescritiva externa à escola, mas sim uma construção coletiva que não é fixa e nem linear.

No Brasil, vivemos muitos momentos contra a configuração de um currículo básico e comum a todos. Lutas contra os Parâmetros Curriculares Nacionais (PCN) e, recentemente, contra a Base Nacional Curricular Comum (BNCC) são exemplos bem claros desse 
movimento. Tais lutas são notadamente possíveis graças à abertura democrática do país na década de 1980. A obra de Paulo Freire já nos mostrava um caminho possível para que o currículo fosse construído de forma aberta e flexível, um currículo construído pelos sujeitos políticos, de inacabamento e inconclusões no momento em que pensa a construção coletiva em cada cotidiano com a configuração de temas geradores construídos pelo povo, em um movimento de "vir a ser currículo". Assim, o diálogo horizontalizado é fundamental.

O diálogo é este encontro dos homens, mediatizados pelo mundo, para pronunciá-lo, não se esgotando, portanto, na relação eu-tu. Esta é a razão por que não é possível o diálogo entre os que querem a pronúncia do mundo e os que não a querem; entre os que negam aos demais o direito de dizer a palavra e os que se acham negados deste direito. É preciso primeiro que, os que assim se encontram negados no direito primordial de dizer a palavra, reconquistem esse direito, proibindo que este assalto desumanizante continue (FREIRE, 1987, p. 137).

A partir do jogo antagônico existente entre os sujeitos, podemos promover sentidos de currículo construídos no cotidiano marcado pelo diálogo, não um diálogo que destrói o outro (de A para B), mas um diálogo que luta com o outro e que promove construções coletivas com o outro (de A com B). Desse movimento dialógico aberto e provisório, surgem, por exemplo, os temas geradores, que, para Paulo Freire,

podem ser localizados em círculos concêntricos, que partem do mais geral ao mais particular. Temas de caráter universal, contidos na unidade epocal mais ampla, que abarca toda uma gama de unidades e subunidades, continentais, regionais, nacionais, etc., diversificadas entre si. Como tema fundamental desta unidade mais ampla, que poderemos chamar "nossa época", se encontra, a nosso ver, o da libertação, que indica o seu contrário, o tema da dominação. (FREIRE, 1987, p. 154).

Os temas geradores (construção de um currículo em permanente movimento) nascem da ação dialógica constante de temas do nosso tempo, diversificados e que atendem e entendem o que os sujeitos vivem, tema da libertação primeira em Paulo Freire. A investigação é feita no devir e não como algo dado e acabado. O diálogo permite a descoberta e construção coletiva. Assim, currículo se torna uma não fixação em um único bem comum a todos.

Uma leitura freiriana do currículo rechaça a ideia de Base, mas não apaga a sua discussão e articulação. Ela não localiza apenas uma crítica severa ao governo que não faz uma propositura dialógica com os sujeitos, mas problematiza as construções coletivas na escola.

Em Pedagogia do Oprimido, a nosso ver, as questões sobre currículo se tornam mais evidentes. Paulo Freire constrói nessa obra a possibilidade de pensar o currículo para além do ensino conteudista e pragmático. Conceitos como dialogicidade, círculo de cultura, tema 
gerador, educação bancária, dentre outros, possibilitam a construção de um currículo como a vir a ser, como algo não dado, mas criado coletivamente, currículo como negociações de sentidos entre os sujeitos, que dele se faz e faz os outros.

A construção do currículo, nesse sentido, faz-se com o outro e não para o outro. $\mathrm{O}$ diálogo horizontal é a condição para que se possa efetivamente pensar a prática de liberdade do processo educativo. São nessas negociações, construídas na democracia, que é possível atingir uma educação de qualidade. Esse espaço-tempo é marcado pela inquietação na construção curricular, uma "inquietação em torno do conteúdo do diálogo é a inquietação em torno do conteúdo da educação" (FREIRE, 1987, p. 47), ou seja, um diálogo horizontal com o outro e não para o outro, uma luta com o outro e não para o outro. Nesse sentido, educar não é limitar a transferência de um conteúdo dado, fixo, mas a construção com o outro de um conteúdo para a transformação de si e do outro.

Assim, o círculo de cultura se torna o espaço tempo de democracia na construção dos saberes necessários para a prática de liberdade, pois “os participantes do círculo de investigação vão extrojetando, para força catártica da metodologia, uma série de sentimentos, de opiniões, de si, do mundo e dos outros" (FREIRE, 1987, p. 64), permitindo que as negociações sejam estabelecidas, que hegemonizações provisórias sejam construídas; nesse sentido, um currículo que esteja pronto para ser consumido, um currículo a ser seguido, um currículo a ser repetido.

O currículo se constrói na luta dentro do círculo cultural e é ali que as palavras, os temas geradores nascem para o processo educativo. Esses círculos, como sinaliza Paulo Freire, "não são uma criação arbitrária" (FREIRE, 1987, p. 50), mas sim a própria encarnação da libertação dos sujeitos na construção curricular. O tema gerador, construído no diálogo com o outro, rompe com as amarras da educação bancária, a qual perversamente tenta limitar os sujeitos de terem uma educação como prática de liberdade, ou seja, da formação de sujeitos marcados pelos sentidos políticos que irão construir e (re)construir as políticas que os cercam.

Chegamos ao ponto que o currículo não será algo construído por experts, mas ele será construído no jogo político. O currículo será pensado e construído no terreno democrático que permite a negociação entre todos os sujeitos. É projetado nesse espaço-tempo, um horizonte que não será conquistado, pois o movimento democrático, sua flexibilidade, irá fazer com que os sentidos acerca do currículo sejam estabelecidos no jogo político entre os sujeitos. 


\subsection{EMANCIPAÇÃO: O INACABAMENTO DO SER}

Pedagogia da autonomia (2002) é uma obra que reúne uma série de pensamentos interessantes de Paulo Freire para a prática docente. Dividido em três partes, o livro carrega uma densidade conceitual prática para a organização política pedagógica da escola e para análises em pesquisas acadêmicas. Há um avivamento da relação práxica entre os educandos e os educadores, uma reflexão profunda sobre a educação bancária e um comprometimento com a especificidade humana no processo de construção de aprendizagens na/para a vida.

Paulo Freire coloca em suspeição um dos principais conceitos da modernidade: a emancipação do sujeito. Parece contraditório, pois Paulo Freire luta, em várias de suas obras, pela emancipação dos sujeitos, contudo, é a emancipação completa que está em voga, uma vez que este sujeito vive e convive em vários espaços-tempos diferentes, ou seja, sua relação de emancipação e autonomia são negociáveis, são provisórias, dependem das relações sociais, culturais, políticas, dentre outras, que os sujeitos se encontram.

Os pontos levantados nessa obra não são somente para o processo formativo docente, mas eles transcendem este processo e problematizam a educação como um todo, fato que podemos articular dentro desse permanente processo de negociação as questões sobre currículo e sobre gestão escolar. O currículo e a gestão escolar são potencializados no momento em que nos desvencilhamos da ideia de fixação em torno de um ideário comum. Pensar que precisamos de emancipação, mas saber criticamente que esta não é permanente nos permite a (re)negociar nossas práticas pedagógicas permanentemente. Paulo Freire destaca esse processo com aventura, com desfecho incerto, marcado por riscos da aventura.

\footnotetext{
Como professor crítico, sou um "aventureiro" responsável, predisposto à mudança, à aceitação do diferente. Nada do que experimentei em minha atividade docente deve necessariamente repetir-se. Repito, porém, como inevitável, a franquia de mim mesmo, radical, diante dos outros e do mundo. Minha franquia ante os outros e o mundo mesmo é a maneira radical como me experimento enquanto ser cultural, histórico, inacabado e consciente do inacabamento (FREIRE, 2002, p. 50).
}

Paulo Freire nos permite pensar e problematizar as nossas pretensas certezas quando pensamento a educação. Para além disso, possibilita-nos discutir com franqueza e tranquilidade as diferenças dos outros e as nossas mesmas que aparecem e reaparecem nos diálogos com outros. Nesse sentido, a produção de currículos e gestões escolares são sempre fruto de negociações "por vir a ser" no cotidiano, pois sempre estarão marcados por posições 
inacabadas, por posições de sujeitos que mudam radicalmente quando mantém articulações com outros.

Esse inacabamento consciente permite sair da lógica que encara o currículo da escola como aquele repertório historicamente construído a ser repassado ao outro, bem como a construção de uma gestão democrática calcada em princípios únicos. Como sujeitos inacabados, podemos ser mais na construção coletiva do currículo em cada contexto escolar, bem como inventar outras formas democráticas para atender às demandas coletivas que cada escola acredita e defende, permitindo ver a emancipação com algo "por vir".

O inacabamento pode potencializar análises em pesquisas sobre currículo e gestão escolar quanto aos sentidos provisórios que cada escola pode produzir e construir, afastando-se de análises que pretendem ditar o que a escola deve fazer no seu dia a dia. Pensar a partir do inacabamento do sujeito nos permite redirecionar o olhar sobre os processos educativos, dando-nos a possibilidade de encetar práticas para os campos do currículo e da gestão escolar que vão além de processos de instrumentalização.

\section{CONCLUSÃO}

Ao buscarmos como objetivo a análise das concepções pedagógicas que poderiam contribuir para a abertura de questões curriculares e de gestão escolar na obra de Paulo Freire, bem como compreender como estes pensamentos podem se localizar em uma perspectiva pós-moderna crítica, chegamos a conceitos potentes para os campos, todos eles assentados no pensamento pós-moderno crítico, ou seja, conhecimentos que reconhecem os diferentes e as diferenças.

A trajetória de Paulo Freire revela a não fixação de suas ideias, ao contrário, partindo de seu pressuposto do inacabamento do ser, e também de sua opção ética, ele não se limita a pensar a educação como revolucionária, pelo contrário, cria e recria a todo o momento, num movimento permanente posições críticas que nos ajuda a pensar as múltiplas revoluções que fervilham o cenário educativo.

Paulo Freire nos coloca a pensar a realidade como um infinito mundo de possibilidades em que nos sujeitos mulheres e homens são também infinitamente capazes de mudar este mundo que não está pronto e acabado. No contexto escolar, há então um infinito movimento de construção coletiva, fato que não nos permite dizer como a escola deve fazer ou ser, mas sim de nela mesma compreender suas construções. E isso é visto na constituição 
da democracia radical vista dentro das obras freirianas analisadas, o que nos permitiu sinalizá-las dentro de uma crítica pós-moderna crítica.

Os conceitos/pensamentos freirianos presentes na discussão nos permitem dizer que as questões curriculares e de gestão escolar podem ser analisadas sob uma perspectiva aberta e flexível, deixando o "por vir" construir as relações cotidianas na escola. Elas desestabilizam intenções que fixam sobre como deve ser o currículo escolar e como deve ser a gestão escolar. E, mesmo pretensamente apresentando uma ideia de como tais áreas devam ser, a desconstrução nela mesma já se faz presente no permanente inacabamento do ser, tais como os presentes na constituição dos temas geradores, que, a nosso ver, são propulsores para a construção do conhecimento de emancipação, pois reconhecem a diferença, o que nos faz acreditar na efetivação do pensamento crítico não totalizante.

É por isso que sinalizamos e questionamos a possibilidade de localizar (e não acorrentar) o pensamento de Paulo Freire nos conceitos/pensamentos apresentados de pós-moderno progressista/crítico, pois ele é marcado pelas possibilidades de construções coletivas pelo movimento dos sujeitos viventes em cada contexto escolar. Deixamos claro que dizermos isso não significa o abandono da luta social fortemente presente na obra de Paulo Freire, mas traz destaque à sua ampla visão desestabilizadora de fixações eternas na luta política contra as mazelas do mundo, acreditando sempre no inacabamento do ser, ou seja, da descentralidade da constituição das pessoas. Por isso, para a escola, Paulo Freire, defende radicalmente a necessidade de rompimento com as tradições pedagógicas que tão fortemente ainda marcam presença no diário mundo escolar, quer seja na nas políticas propostas de gestão, para o currículo, quer seja na gestão das escolas ou nas salas de aulas.

Encontra-se, assim, no pensamento freiriano um terreno fértil para pensar questões de currículo e de gestão escolar enquanto produção de práticas pedagógicas no contexto escolar, bem como para as análises das pesquisas nesses campos. Eles não fixam uma única forma de vivenciar esses espaços, coadunando com o movimento que vivemos na contemporaneidade, marcado por lutas diferentes que muitas vezes se articulam em busca de um mundo melhor, em um terreno pós-moderno crítico e não celebratório.

\section{REFERÊNCIAS}

DERRIDA, J. Escritura e diferença. São Paulo: Perspectiva, 1971. 
DERRIDA, J. Gramatologia. São Paulo: Perspectiva, 2004.

DERRIDA, J. Posições. Belo Horizonte: Autêntica, 2001.

FÉLIX, M. F. C. Administração escolar: problema educativo ou empresarial? São Paulo: Cortez, 1989.

FREIRE, P. Pedagogia do Oprimido. 17 ed. Rio de Janeiro: Paz e Terra, 1987.

FREIRE, P. A educação na Cidade. São Paulo: Cortez, 1991.

FREIRE, P. Pedagogia da Autonomia. 25 ed. São Paulo: Paz e Terra, 2002.

GIL, A. C. Como elaborar projetas de pesquisa. 4. ed. São Paulo: Atlas, 2002.

LACLAU, E. A política e os limites da modernidade. In: HOLLANDA, H. B. Pós-modernismo e política. Rio de Janeiro: Rocco, 1991.

LACLAU, E. Emancipação e diferença. Rio de Janeiro: EdUERJ, 2011.

LACLAU, E; MOUFFE, C. Hegemonía y estratégia socialista: hacia uma radicalizacion de la democracia. 3 ed. Buenos Aires: Fondo de Cultura Económica, 2011.

LOPES, A. C. Teorias pós-críticas, política e currículo. Educação, Sociedade, Culturas, $n^{\circ}$ 39, 7-23. 2013.

LOPES, A. C. e MACEDO, E. F. Teorias de Currículo. São Paulo: Cortez, 2011.

LIMA, T. C. S.; MIOTO, R. C. T. Procedimentos metodológicos na construção do conhecimento científico: a pesquisa bibliográfica. Rev. Katályses. Florianópolis v. 10 n. esp. p. 37-45. 2007.

LÜDKE, M.; ANDRÉ, M. E. D. A. Pesquisa em educação: abordagem qualitativa. São Paulo: EPU, 1986.

LYOTARD, J. A condição pós-moderna. 12 ed. Rio de Janeiro: José Olympio, 2009.

MOUFFE, C. En torno a lo político. Buenos Aires: Fondo de Cultura Económica, 2011.

MOREIRA, A. F.B. Currículos e programas no Brasil. São Paulo: Papirus, 1990.

PARO, V. H. Administração escolar: introdução crítica. São Paulo: Cortez: Autores Associados, 1986.

PETERS, M. Pós-estruturalismo e filosofia da diferença. Belo Horizonte: Autêntica, 2000.

RIBEIRO, J. Q. Ensaio de uma teoria da administração escolar. São Paulo: Saraiva, 1953. 
SANTOS, B. de S. Por que é tão difícil construir teoria crítica? Revista Crítica de Ciências Sociais, n. 54, p. 197-215, 1999.

TEIXEIRA, A. Pequena introdução à filosofia da educação: a escola progressiva ou a transformação da escola. 8. ed. São Paulo: Editora Nacional, 1978.

TEIXEIRA, A. Educação para a democracia: introdução à administração educacional. 2 . ed. Rio de Janeiro: Editora UFRJ, 1997.

TYLER, R. Princípios básicos de currículo e ensino. Porto Alegre: Globo, 1983. 